\title{
Evaluating the Succeeded Rate of Reviving Identity Plans of Lost Spaces Using the Analytical Hierarchical Process (The Center of Akhoond District)
}

\author{
Mohammadreza Sadeghi Moghaddam ${ }^{1, *}$, Mohadese Yazdipour $^{2}$, Elahe Yazdiha $^{3}$, Salameh Azimi $^{4}$ \\ ${ }^{1}$ Department of urban planning, Qazvin Branch, Islamic Azad University, Qazvin, Iran \\ ${ }^{2}$ Young Researchers and elite Club, Qazvin Branch, Islamic Azad University, Qazvin ,Iran \\ ${ }^{3}$ Urban Planning, Researcher of Construction Industry Research Center of Qazvin Islamic Azad University \\ ${ }^{4}$ Faculty of Industrial and Mechanical Engineering, Qazvin Branch, Islamic Azad University, Qazvin, Iran \\ *Corresponding Author: m.sadeghi62@gmail.com
}

Copyright (C) 2014 Horizon Research Publishing All rights reserved.

\begin{abstract}
Lost urban spaces are unique spaces inside the city which have not been used at all or significantly. In other words, they are unpleasant urban areas which have no positive relationship with surrounding environment and users in redesigning process of spaces. Hence, organization and reclamation of lost and left spaces through performance injection from resources and wealth which give identity is a part of technologies which can be experienced and tested by experts in order to provide places for presence, spending time, observing and be seen from these excluded urban spaces. With this description and the importance of the subject, the present paper sought to introduce urban lost spaces and consider criteria in order to revive identity in these spaces using Analytical Hierarchical Process (AHP) model and also to consider the succeeded level of the recovery plan of identity in Akhoond district in Qazvin using a descriptive-analytical method. The results of the present study indicated that the recovery plan of identity in Akhoond district was not successful due to the lack of attention to main criteria of giving identity to spaces and it has not transferred identity, mobility and fixation to its residents.
\end{abstract}

Keywords Urban Lost Spaces, Identity, Akhoond District of Qazvin, Analytical Hierarchical Process (AHP)

\section{Introduction}

Nowadays, cities are faced with a big problem in the field of urban planning. Urban spaces have lost their roles. Spaces which were most social spaces of the city in not too distant past are changed into the oldest areas of the city nowadays and cannot find their real places after the city development and do not have any effective role in the new urban life [1]. Some definitions of unused urban space emphasize the emptiness of the terrain, compared to the surrounding built environment, the fact that they are not occupied by neither people nor construction and infrastructure [2]. On the other hand, since "identity" is a set of attributes and characteristics which results in "identity" of a person or a community of people and other communities, the city, also finds identity and become independent following this criterion. Generally, the subject of identity and specifically, urban identity is one of the subjects which are very important due to its role in identifying people. Urban identity crisis is disturbingly feeling despite the importance of this subject in recent years [3].

Therefore, considering the importance of this subject and since most urban lost spaces lack identity and desirable function for users nowadays, the present paper tried to consider the succeeded rate of one of the recovery plans of identity in these spaces using descriptive-analytical method and library studies (taking notes) and field method (observation, interview, questionnaire and etc.) and presenting some criteria which give identity.

\section{Definition of Urban Identity}

Urban identity is a reflection of all the local people's traditions, culture, aspirations grouped together. It reflects their needs, their successes, their failures and their future. Constricted, the city is understood and interpreted through the technical rather than the sensory, yet it is the sensory from which we build feeling and emotion. Cultural identity in contrast to individual identity concentrates on groups or social systems. By that, space is one of the most important preconditions to develop cultural identity $[7,8]$.

The notion of "identity" involves numerous determinants such as those of political and social order. As such, it seems to be a "complex adaptive system". Since cities are constantly changing, and evolving new forms, their urban identity is created through the complex interaction of natural, 
social and built elements. Therefore, the urban environment has to be considered from a historical perspective, not merely by understanding historically significant buildings, but rather through the evolution of the local urban context, with respect to human activity, built form, and nature. There were many approaches to the identity modernism debate.

\subsection{Basic elements of the urban identity:}

The static physical setting, the activities, and the meaning constitute the three basic elements of the urban identity of places $[9,10]$.

The first two of these elements can probably be easily appreciated, but the component of meaning is much more difficult to grasp. Much more focus must be put on the sense of place which is the aura and impression of this place. Meaning and character have more than a purely visual or spatial dimension, and they cannot be instantly achieved by the implementation of a new urban design scheme. Thus the physical component can be understood as comprising nature and the built environment. Similarly activities can be distinguished as being creative, destructive or passive. Meanings can change and be transferred from one set of objects to another, and they possess their own qualities of complexity, obscurity, or clarity. Since place identity is a sub-structure of the self-identity of the person consisting of broadly conceived cognitions about the physical world in which the individual lives. These cognitions represent memories, ideas, values, meanings, and conceptions of behavior and experience. The Arab urban \& architectural features could be analyzed according to the previously mentioned elements as follows [11]:

\section{Physical Settings:}

- Tendency to look inwards - Architecture of courtyards and enclosed spaces.

- The use of geometric shapes and repetitive art.

- The use of warm colors.

- Passive environmental management

- Dense Fabric

\section{Activities:}

- Public festivals, fairs \& family picnics.

- Cultural plazas for public speeches and festivals.

Meaning:

- Private yet integrated community

- Religious spirit

\section{The Definition of Lost Spaces}

Lost spaces are urban undesirable areas which have no positive relationship with surrounding environment and users in the process of redesigning spaces. On the other hand, these spaces give many opportunities to designers in order to urban redeveloping and recreating for rediscovering many hidden sources in cities [4].

Based on the other definition, lost spaces are some of physical and social spaces which have not been managed well and properly and damaged mental image of people from that district. Actually, lost spaces are spaces without clear definition and boundaries which have no relationship with urban elements [5].

Lost space are also the abandoned waterfronts, train yards, vacated military sites, and industrial complexes that have moved out to the suburbs for easier access and perhaps lower taxes. They are the vacant blight-clearance sites- remnant of the urban -renewal days- that ere, for a multitude of reasons, never redeveloped. They are the residual areas between districts and loosely composed commercial strips that emerge without any one realizing it. Lost spaces are deteriorated parks and marginal public housing project that have to be rebuilt because they do not serve their intended purpose[6].

Lost spaces are classified into two groups of material (superficial) and semantic (conceptual) in an overall classification:

\subsection{Material Lost Spaces (Superficial)}

Actually, as Roger Trancik points out, this classification of spaces include those kinds of spaces which occupy subjective spaces and are visible in three groups:

A: Physical (building aggregate), a building which is available but is lost due to the lack of appropriate use.

B: The fields which have public possession and are the remained urban land among the aggregates and fields and do not have determined boundaries.

C: The fields which lack appropriate use despite having public or private possession, determined boundaries and being capable of recognition.

\subsection{Semantic Lost Spaces (Conceptual)}

Trancik also remarked about this field that they are related to spatial characteristics of a space. Although they are not obvious and clear, they exist uniquely in unconscious mind of human without any doubt and have specific place in collective memory of citizens which itself consists of two classifications:

1-Forgotten values: Actually, they include characteristics, qualities and /or important buildings which existed in old city and no trace have been left from those evocative elements nowadays and/or they changed into indicators for naming that places and there are a lot of these cases in cities.

2- Hidden values: Trancik briefly mentioned about this subject in human spaces that whenever physical qualities acted poorly and/or incompletely in response to human needs of space, that space can be considered as a lost space [1].

\section{Giving Identity to Urban Lost Spaces}

Creating urban identity means maintaining the concept of 
a determined structure and organization which is understandable and enjoyable for people. Since different people use different ways for creating structure and organizing surrounding environment, the claimed organization or structure of a urban environment and/or a city must not be dependent on a unite, but different and effective factors in this structure must be on each other and penetrate to each other like different layers in order to create a conceptual and meaningful network and totality [12].

The urban identity of a community is an exceptionally valuable component of sustainable urban-cultural development [13].

Self-identity is also viewed as the outcome of personal interaction, in which the person enters consciousness of self through the evaluative responses of others, a position maintained by many identity theorists [14].

Moreover, in order to give identity to cities and urban spaces, theoreticians mention different layers and indicators such as events and collective memories, transparency and compatibility, permeability, visibility and readability, variety and economic diversity and frequency of activity, flexibility, security, social solidarity, participation in various affairs, paying attention to district and growth of neighborhood-orientation, paying attention to spaces and general and public fields, dynamism and mobility, mixing efficiencies, urban face and landscape, and ... and also believe that strengthening lasting impression, achieving cultural independence, dynamism and mobility of social communication, sustainable living, and overcoming homesickness and nostalgia, strengthening neighborly relations and in other words strengthening human relationship with the city are considered among the effective factors on identity [15].

The public arena is formless and unable to support any of the basic functions of interactive city life. As a result residents struggle to locate themselves culturally and are unable to engage positively with their pasts and / or futures. This in turn has a negative impact on the social relationships that are so critical to the survival of the urban poor in our current context[16]

Reproducing approach of urban spaces is a new look at spaces within city so that it can provide places for presence, spending time and creating belonging sense with small change of physical-spatial and creating environmental qualities in many excluded spaces such as lost spaces. Many environmental and spatial qualities form field and potential of these changes which are hidden in these spaces. Moreover, recognizing and strengthening them along with changing them into fresh and presentable urban spaces can be patterns for creating new space which finally result in forming identity in these kinds of spaces.

On the other hand, the identity of any phenomenon consists of two basic components of subjective and objective [16].

Therefore, some parts of subjective and objective criteria are considered in the subject of identity of urban and lost spaces.

\subsection{Subjective Criteria}

Subjective examples mean visible physical symptoms of landscape. In addition, subjective variables which are related to combining aspects and formal components are more effective than objective variables which are related to observer, his understanding, beliefs, values and mind in aesthetic preference [17].

In identifying the urban identity, its objective factor which is the city, urban structure and framework, public space, permeability, environmental characteristics and ... must be considered and studied that some of them are considered in the following parts

\subsubsection{Permeability}

Urban planners pay special attention to fear of lacking access to services and permeability of urban context as a quantitative criterion through issues such as security, reducing response time to emergency services and reducing anxiety caused by perplexity. Various indicators are used in this field that many of them generally estimate the quality connection in contexts of cities [18].

More permeability concerns the place. The belonging sense in this function guide shows the importance of individual understanding toward space in affection and intervention of people in special places for increasing utility and belonging sense to the place [19].

\subsubsection{Environmental Characteristics}

Urban green space becomes more important for urban environment and urban ecosystem [20].

Nature is the live litter of human and urban life and therefore, it can have a key role in giving identity to the cities [21].

\subsubsection{Physical Characteristics}

Another method which is used in studying the identity of artificial environment is only a physical method and based on the observation of a researcher. Physical identity means properties and characteristics which non-differentiate the body of city and uncover its similarity with its own [22]. Therefore, issues such as coordinator and appropriate lighting, using appropriate floor for pedestrians, making furniture proportional to space, from variety, building views and ... are considered in order to analyze the identity of urban spaces from physical aspect.

\subsection{Objective Criteria}

Objective criteria mean processes of understanding, identifying and feeling. They are experimental and test hypotheses and trends and also visible following understanding the human preferences in identifying physical components. So, subjective criteria are more attractive than objective criteria in preference of spatial identity [23].

Therefore, in order to recognize objective criteria which give identity such as residential social groups, the level of 
understanding and social consciousness and their expectations and demands, the rate of readability, the sense of belonging, public participation and ... are considered that some of them are mentioned here in order to consider the identity of studied lost spaces.

\subsubsection{Security}

Security is the sense of tranquility, confident, and release from any kind of fear, threat and panic in public fields of cities [24].

\subsubsection{Belonging Sense}

The space must accompany its audiences over time and therefore it must always create the sense of belonging and convenience which are the results of this companionship. It is in accompaniment of space with audience that space keeps its routine with people. Continuing consolidation of this companionship results in strengthening the identity [25].

Factors such as duration of residence in place, having friends or relatives near there are affective in the rate of belonging sense to living place and desire to leave in order to consider the indicator of belonging sense of people to living place [26].

\subsubsection{Public Participation}

The subjective and emotional participation of people in group situations motivate them in order to help each other to achieve group goals and participate in job responsibilities [27].

Participation augments the power of citizens and people in general by involving them in deliberation processes and it enables them to take an active role [28].

Table 1. Classification of giving identity criteria to space

\begin{tabular}{|c|c|}
\hline \multicolumn{2}{|c|}{ Criteria of Giving Identity to Space } \\
\hline Objective Criteria & Subjective Criteria \\
\hline $\begin{array}{c}\text { Security } \\
\text { The sense of tranquility, confidence, } \\
\text { an freedom from any kinds of fear, } \\
\text { threat and panic in public fields of } \\
\text { cities }\end{array}$ & $\begin{array}{c}\text { Permeability } \\
\text { Availability of the space and } \\
\text { part of the selection by the } \\
\text { environment for changing the } \\
\text { place of people } \\
\text { Physical Elements }\end{array}$ \\
$\begin{array}{c}\text { The sense of Belonging } \\
\text { Duration of residence in a place, } \\
\text { the rate of fixation to the life } \\
\text { environment and desire to leave } \\
\text { and ... }\end{array}$ & $\begin{array}{c}\text { Characteristics and properties } \\
\text { for differentiating the body of } \\
\text { the city from the others and } \\
\text { detection of similarities with } \\
\text { itself }\end{array}$ \\
$\begin{array}{c}\text { Public Participation } \\
\text { Encouraging toward expressing the } \\
\text { wishes of the people and active } \\
\text { performance according to their } \\
\text { needs }\end{array}$ & $\begin{array}{c}\text { Chvironmental } \\
\text { Characteristics } \\
\text { The place of human lives and } \\
\text { city life and the key role in } \\
\text { giving identity to it }\end{array}$ \\
\hline
\end{tabular}

\section{Methodology}

This research uses an inductive, deductive and using the Analytical Hierarchical Process methodology through data collection to achieve a deeper understanding about identity, urban identity and different approaches to revive the urban identity plans of lost spaces. This could be done by analyzing the local adaptations and additions done to already existing spaces through field visits and interviews with people to understand their points of view and needs. Through an analytical methodology a relevant example that attempt to reinvent the local identity will be studied.

\section{Analyzing the Sample (The Center of Akhoond District in Qazvin)}

\subsection{Introducing the Akhoond District}

Akhoond district is one of the traditional and oldest contexts of Qazvin which still have retained its traditional context. The history of this district relates to the Safavid era and it is placed at the Southwest of Qazvin with the area of approximately 1600 square meters. Moreover, the plan of improvement and reclamation of this district was implemented by municipal of Qazvin in 2008 along with reclamation of historical identity of the city and old districts.

\subsection{Analysis}

The architecture in the complex is very impressive and is in good condition. It undergoes maintenance regularly. The complex is surrounded by a fence wall of Islamic designs to ensure security at night. There are multiple entrances that lead to the complex. There is an entrance from all 4 sides of the zone, therefore facilitating accessibility. Only a small part of it allows the entrance of vehicles. The rest of it is a pedestrian only zone. The surroundings are mostly residential buildings of medium density and of no special architectural style. The plaza is elevated with almost 20 steps giving it a good surrounding view. It overlooks three mosques and two public gardens. It acts as the central space that binds all these mosques and spaces together. The elevated plaza is accessed by 3 staircases from different nodes. Underground shops and cafes are available under the plaza. If the mosque complex zone undergoes strong rehabilitation, it could be one of the most successful projects in Alexandria as it would attract many tourists and it would be a good representative of the local urban identity. By analyzing this urban space to identify the strengths \& weaknesses as follows:

\section{Strengths}

- Site surrounded by four streets makes it easily accessible

- The site is in an active, integral part of the city

- The complex can be reached by public transportation

- The presence of large green areas

- The complex includes several landmarks \& is considered as a node.

- The public spaces are inviting $\&$ attractive.

Weaknesses

- The plaza is viewed as a pass through and not a 
destination

- The gates doesn't invite the outdoor community to enter the park or the plaza

- Absence of seating, signage and street furniture in the park

- Absence of tenants \& activities in the plaza

- Inadequate shading \& lighting for the plaza

- No permanent security provided

- Low quality finishing for the plaza.

- Absence of parking spaces

Lack of maintenance $\&$ cleanness

- Lack of identity and character.

- The street fair blocks the street sometimes.

\subsection{Analyzing the Succeeded Rate of Giving Identity Project to Akhoond District}

In the following, the succeeded rate of the plan of identity recovery plan of the center of this district which has been known as a lost space among residents of this place and other people before 2008 will be considered according to overview of the mentioned district. In order to do this, some criteria and indicators were considered based on the goals of the present paper for success of a project of giving identity and the weight of each of them will be determined according to the comparison of criteria with each other (Table 3 ) through 9-hourly quantity for binary comparison of options (table 2) using Analytical Hierarchical Process (AHP) and Expert Choice Software.

Table 2. 9-Hourly Quantity for Binary Comparison of Options [28]

\begin{tabular}{|c|c|}
\hline Definition & Rating (strongly preferred) \\
\hline equally preferred & 1 \\
\hline moderately preferred & 3 \\
\hline strongly preferred & 5 \\
\hline very strongly preferred & 7 \\
\hline extremely preferred & $966 \times 4$.2 \\
\hline $\begin{array}{c}\text { Intermediate preferences (when } \\
\text { there is a moderate position) }\end{array}$ & \\
\hline
\end{tabular}

In the following, the effect of implementation of the plan is considered based on mentioned criteria through interviewing residents and analyzing the available statistics and results in the plan of identity reclamation of the center of

Akhoond district and the rate of achieving each of these criteria with following coefficients for the considered restrict (Table 5) according to intervals of assessment (Table 4):

Table 3. Weight of Each Criteria of Giving Identity

\begin{tabular}{|c|c|c|c|c|c|c|c|}
\hline \multirow{2}{*}{ Criteria } & \multicolumn{3}{|c|}{ Subjective Criteria } & \multicolumn{3}{c|}{ Objective Criteria } \\
\cline { 2 - 8 } & Security & $\begin{array}{c}\text { Belonging } \\
\text { Sense }\end{array}$ & $\begin{array}{c}\text { Public } \\
\text { Participation }\end{array}$ & Permeability & $\begin{array}{c}\text { Physical } \\
\text { Characteristics }\end{array}$ & $\begin{array}{c}\text { Environmental } \\
\text { Characteristics }\end{array}$ & priority \\
\hline Security & 1 & 2 & 3 & 2 & 4 & 5 & 0.249 \\
\hline Belonging Sense & $1 / 2$ & 1 & 4 & 3 & 5 & 6 & 0.380 \\
\hline $\begin{array}{c}\text { Public } \\
\text { Participation }\end{array}$ & $1 / 3$ & $1 / 4$ & 1 & 2 & 2 & 3 & 0.100 \\
\hline Permeability & $1 / 2$ & $1 / 3$ & $1 / 2$ & 1 & 3 & 3 & 0.159 \\
\hline $\begin{array}{c}\text { Physical } \\
\text { Characteristics }\end{array}$ & $1 / 4$ & $1 / 5$ & $1 / 2$ & $1 / 3$ & 1 & $1 / 3$ & 0.070 \\
\hline $\begin{array}{c}\text { Environmental } \\
\text { Characteristics }\end{array}$ & $1 / 5$ & $1 / 6$ & $1 / 3$ & $1 / 4$ & & 0.041 \\
\hline
\end{tabular}

Table 4. Assessment Intervals of the Achievement Rate of Criteria

\begin{tabular}{|c|c|c|c|c|}
\hline Very weak & Weak & Average & Good & OK \\
\hline$(2-0)$ & $(4-2)$ & $(6-4)$ & $(8-6)$ & $10-8)$ \\
\hline
\end{tabular}

Table 5. The Achievement Rate of Criteria in the Center of Akhoond District

\begin{tabular}{|c|c|c|}
\hline Security & Weak & 2 \\
\hline Belongig Sense & Average & 4 \\
\hline Public Participation & Weak & 3 \\
\hline Permeabiliy & Weak & 6 \\
\hline Physical Characteristics & Good & 1 \\
\hline Environmental Characterstics & Very weak & 2 \\
\hline
\end{tabular}


Finally, weight values of criteria were multiplied by each coefficient and the final weight was calculated in order to evaluate the succeeded rate of the plan of giving identity to the center of Akhoond district (Table 6):

Table 6. The Final Weight of Criteria of Giving Identity to the Center of Akhoond District

\begin{tabular}{|c|c|}
\hline Criteria & Final Weight \\
\hline Security & 0.498 \\
\hline Belongig Sense & 1.52 \\
\hline Public Participation & 0.2 \\
\hline Permeabiliy & 0.477 \\
\hline Physical Characteristics & 0.42 \\
\hline Environmental Characterstics & 0.041 \\
\hline Total & 3.156 \\
\hline
\end{tabular}

\section{Conclusion}

Recognizing environmental qualities which are hidden in lost spaces of cities and the possibility of using them so that the lost spaces change into presentable spaces can be an appropriate approach in building contemporary of modern cities so that cities change into lively urban spaces in line with the needs of the residents. Therefore, 6 criteria of giving identity including security, the sense of belonging, public participation, permeability, physical elements, and environmental characteristics in achieving the succeeded rate of the plan were considered according to conducted studies in the center of Akhoond district which was considered as a lost space before 2008 and reclamation of its identity. After interviewing the residents and considering the results of the questionnaires, it was indicated that this space was not welcomed much by its residents after its reclamation and it did not have enough security and Appropriate permeability for its residents. However, its Physical elements such as appropriate furniture and lighting were somewhat considered. Therefore, after considering all the mentioned criteria, it was revealed that the revival plan of identity of the center of Akhoond district did not have much success and its performance was poor and it did not transfer identity, mobility and the sense of belonging to the residents of that space as it should be.

\section{REFERENCES}

[1] Rahimi, R. and Nour Taghani, A. Discovering lost spaces in old contexts in order to strength en historical contexts. Journal of Architecture and Constructing City. (2006).

[2] Nefs M. Unused urban space: conservation or transformation?
Polemics about the future of urban wastelands and abandoned buildings. City \& Time 2 (1): 4, 2006.

[3] Nofel, A., Kalbadi, P. and Pour Jafar, M. Considering and analyzing effective indicators in urban identity (sample of Jolfa in Esfahan). Journal of Armanshahr. (2009).

[4] Ayatolahi, F. Identifying lost spaces inside the city along with its comparative study in Qom. Journal of Analyzing Papers, 2 (19), (2010).

[5] Poerbantanoe B. The lost-city dan lost-space karena perkembangan pengembangan tata-ruang kota, Dimensi teknik arsitektur. Vol 27, No.2; Desember (1999).

[6] Trancik R, Finding Lost Space,Theories of Urban Design, Van Nostrand Reinhold Company. New York; (1986).

[7] Friedrich S. "Spatial Aspects of Cultural Identity and Social Segregation", TAN2 Conference Report "Cultural Identity and Spatial Segregation; 5-8 Nov (1998).

[8] Schneider A. "Preface and Programmatic Overview", TAN2 Conference Report "Cultural Identity and Spatial Segregation, 5-8 Nov (1998).

[9] Shaftoe H., Convivial Urban Spaces: Creating Effective Public Spaces. Earthscan Publications Ltd; (2008).

[10] Clare C. M., Francis C.), People Places: Design guidelines for Urban Open Space, Wiley; 2nd Edition; (1997).

[11] Asfour. Kh , Identity in the Arab Region (Architects and /or projects from Egypt -Iraq-Jordan -Saudi Arabia-Kuwait and Qatar. Misr International University, Cairo, 2008.

[12] Molavi, M. and Mahjoub, N. (2009). Considering components of identity of Rasht. Journal of the Construction of Qilan Engineering Organization, (51).

[13] Pušić Ljubinko. M. Sustainable development and urban identity a social context. Spatium Journal; (2004).

[14] Watson L. Urbanization and Identity Dissonance: A Guajiro Case, American Anthropologist; October (1972).

[15] Noudeh Farahani, M. Considering effective factors on the identity of new cities, the sample: new city of Pardis. Unpublished Thesis (2006).

[16] Mammon N, Paterson J. Urban space, Memory and The public realm, Presented to the Community Healing Regional Conference hosted by: The Institute for Justice and Reconciliation;Cape. (2005).

[17] Varesi, H., Amel Bafandeh, M. and Mohammad Zadeh, M. (2010). Considering and analyzing the components of urban identity and their relationship with the belonging sense to place of residens of new cities (sample: Golbahar city). Journal of Research and Urban Planning, 1(2).

[18] Amin Zadeh, B. Considering the beauty and place identity. Journal of Urban Identity, 5(7). (2010).

[19] Amin Zadeh Gohar Rizi, B. and Badr, S. Analyzing permeability indicators in urban contexts. Journal of Urban Identity, 6(12). (2012).

[20] Bonakdar, A. and Gheraei, F. Changing the paradigms in urban planning principles: from physical and social and perceptual components to constructing places approach. Journal of Honar University, (6). (2011). 
[21] Rahimioun, A. Giving identity to the city through using natural elements (sample: Hamedan). Journal of Urban Identity, 5(9).(2011).

[22] Mir Moghtadaei, M. The criteria of recognizing physical identity of cities. Journal of Honarhaye Ziba, (19). (2004).

[23] Daneshpour, A. and Fakhari, S. Confronting crimes in urban spaces associated with urban planning tools. Journal of Namad-e-Golestan. (2011).

[24] Behzadfar, M. Urban identity with a look at Tehran identity. Journal of Shahr. (2011).

[25] Vahida, F. and Negini, S. Constructing and finding reliability of the measure of district identity. Journal of Motaleat-eShahri, (2). (2012).

[26] Sadeghi Moghadam, M. Considering the place public participationin constructing city with an emphasis on making places desirable through public participation. Unpublished Thesis, Qazvin. (2009).

[27] Bizjak I. Improving public participation in spatial planning with Web 2.0 tools. Urbani izziv; volume 23, no. 1, (2012).

[28] Zebardast, A. The application of Analytical Hierarchical Process in urban and district planning. Journal of Honarhaye ziba, (10). (2001). 